\title{
Off-label drugs for weight management
}

This article was published in the following Dove Press journal:

Diabetes, Metabolic Syndrome and Obesity:Targets and Therapy

10 June 2017

Number of times this article has been viewed

\section{Ed J Hendricks}

Center for Weight Management, Roseville and Sacramento, CA, USA

Correspondence: Ed J Hendricks

Center for Weight Management, 2510

Douglas Blvd, Suite 200, Roseville, CA

9566I, USA

Tel +l 9162025759

Email edhendricks@surewest.net
Abstract: The global pandemic of obesity and overweight now affects between 2.8 and 3.5 billion of the world population and shows no signs of abatement. Treatment for what is now recognized as a chronic disease includes pharmacotherapy, considered an essential component of comprehensive therapy. New drug discovery is robust, but the pace of the US Food and Drug Administration approval for obesity drugs has been glacial, and only a handful of approved drugs are available for treating obesity. In the last 20 years, the US Food and Drug Administration has approved 208 drugs for cancer, 118 for cardiovascular diseases, 168 for neurological diseases, and 223 endocrinologic drugs, but only 6 for obesity, 2 of which have been taken off market. Currently, there are only 9 drugs approved by the FDA for obesity treatment. US physicians have turned to off-label drug use in their effort to care for increasing numbers of patients with excess adiposity. Phentermine is the most commonly used drug for treating obesity. Although approved only for short-term use, US physicians have used it successfully for long-term since its initial approval in 1959. This drug, used off-label for long-term, has proven to be safe and effective, far safer than the disease it is used to treat. Phentermine and diethylpropion, an equally safe but somewhat less effective drug, are both generic and therefore inexpensive. These drugs have been maligned inappropriately because their two-dimensional structure diagrams resemble amphetamine and also because of unproven presumptions about their potential adverse effects. In the face of an increasing epidemic, worldwide obese and overweight patients deserve effective treatment that prescribing these drugs could provide, if rehabilitated and used more frequently. US physicians will likely continue to use any drug proven useful off-label for this illness until such time as more effective drugs are approved.

Keywords: overfat, obesity, pharmacotherapy, leptin, phentermine, metformin

\section{Introduction to epidemiology of obesity and developments in drug treatment}

The extent of the pandemic of obesity and overweight has been seriously underestimated since most assessments do not include perhaps as many as 2.7 billion patients with excess fat stores but with a body mass index (BMI) below arbitrary cutoffs. These overfat patients are not classified as either overweight or obese. ${ }^{1}$ As will be discussed more thoroughly, these patients, who are overfat but neither overweight nor obese, are ignored and often untreated under the conventional obesity treatment paradigm.

Significant progress has been achieved in understanding the pathophysiologic processes involved in excess adiposity. Noteworthy advances in knowledge in this field include the discoveries that mammalian fat stores are not just inert repositories 
of energy but dynamic organs metabolically active in producing hormones, and that excess adipose tissue releases a storm of molecules that incite protean systemic inflammatory processes.

Lifestyle modification is an important component of comprehensive obesity treatment. One facet of such treatment is improvement and abatement of harmful eating behaviors. Regulation of appetite has been a focus of obesity drug effects but there is now also evidence that some obesity drugs induce beneficial changes in eating behavior. ${ }^{2-4}$ There is also observational evidence that phentermine treatment induces changes in eating behavior, ${ }^{5}$ and that some phentermineinduced eating behavioral changes persist with long-term therapy. ${ }^{6}$ These observations suggest that short- and longterm obesity pharmacotherapy may be an essential adjunct to behavior modification therapy. Additional research in this arena is needed.

Development of new drugs to combat excessive adiposity has been very slow and there have been prolonged delays in approval of new drug by the US Food and Drug Administration (FDA). Currently available anti-obesity drugs include 5 approved for long-term use and 4 for short-term use. ${ }^{7}$

The 4 new drugs for obesity approved by the FDA between 2012 and 2014, including phentermine/topiramate $\left(\right.$ Qsymia $\left.^{\circledR}\right)$, lorcaserin $\left(\right.$ Belviq $\left.^{\circledR}\right)$, naltrexone/bupropion (Contrave $^{\circledR}$ ), and liraglutide $\left(\right.$ Saxenda $\left.{ }^{\circledR}\right)$, have not done as well in the US marketplace as their pharmaceutical company owners hoped and everyone had initially predicted. The acceptance of these new obesity drugs by US physicians has been far below acceptance rates of other new drugs. ${ }^{8}$ Patient acceptance has also been slow to develop.

The costs of development for each of these exceeded US $\$ 1.5$ billion, and the companies now seem to have low expectations of recouping the costs of development before their patents expire. Novo Nordisk has said they intend to market Saxenda long-term but they recently have reduced their sales force marketing the drug to physicians.

Zafgen announced they had halted research on their obesity-drug candidate beloranib in July 2016 after two deaths during trials. Meanwhile, other companies continue searching for other effective weight management drugs. ${ }^{9}$

\section{Current strategies for weight management}

There are 2 slightly differing treatment approaches for weight management in the US. The orthodox paradigm is BMI centric, restricting pharmacotherapy to patients with a BMI equaling or exceeding either $30 \mathrm{~kg} / \mathrm{m}^{2}$ or $27 \mathrm{~kg} / \mathrm{m}^{2}$ in the presence of an excess adiposity-associated disease such as diabetes. Great treatment emphasis is placed on lifestyle modification, and pharmacotherapy is considered a treatment modality ancillary to behavior modification. No emphasis is placed on treating patients with excess adiposity but with a BMI below the thresholds and pharmacotherapy for such patients is off-label.

On the other hand, private obesity medicine practitioners led by the 67-year-old American Society of Bariatric Physicians (ASBP), recently renamed the Obesity Medicine Association, have taken a pragmatic approach to treatment. These physicians prescribe obesity medicines not only for patients with BMIs above conventional cutoffs but also often prescribe obesity drugs off-label for patients who have excess adiposity with BMIs below orthodox thresholds. Biannual ASBP courses had taught several generations of physicians to use measures of excess fat for treatment decisions before a 1985 US National Institutes of Health Consensus Conference suggested BMI cutoffs for diagnosis of overweight and obesity and an expert committee of the World Health Organization recommended in 1995 defining obesity more simply by a BMI at or above $30 \mathrm{~kg}$ / $\mathrm{m}^{2}$. Thus, when in 1999 the FDA abruptly required all labels for obesity drugs to include BMI thresholds as indications for prescribing, the practitioners found that they were using the obesity drugs off-label for many of their patients.

The use of BMI thresholds for diagnosis and treatment decisions is controversial. It is known that a BMI of 30 as a test for indicating the treatment of excess adiposity has a very high specificity, but has a very low sensitivity. Body weight or indices of body weight are only indirect assessments of adiposity. Body fat can be measured directly by a variety of methods, including skin calipers, biologic impedance, underwater weighing, and dual-energy X-ray absorptiometry (DXA), which is the most accurate. Body fat $>25 \%$ of total weight in men and $>30 \%$ in women is generally considered excessive, although there is not wide agreement on these values. BMI as a measurement of adiposity compares unfavorably with the various direct measures of body fat. It has been estimated that a BMI cutoff of $30 \mathrm{~kg} / \mathrm{m}^{2}$ identifies only $50 \%$ of those who have increased cardiovascular risk due to adiposity..$^{10} \mathrm{BMI}$ significantly underestimates adiposity compared with DXA, ${ }^{11}$ or other direct adiposity measures. ${ }^{12}$

Other arguments advanced for drug treatment according to excess adiposity as opposed to using BMI include the fact that excess adipose tissue accumulation is associated with an immune response that results in widespread systemic inflammatory changes that damage distant tissues and induce a host of complicating diseases. An immune process appears 
at a very early stage of adipose accumulation, ${ }^{13}$ which then induces slowly progressive systemic inflammation. The pragmatic approach, which acknowledges that excess adiposity is most often progressive, is to treat with pharmacotherapy early while the patient is overfat but not yet overweight or obese, whereas the orthodox approach delays treatment withholding pharmacotherapy until adipose-induced inflammatory processes are irreversible.

Physicians following either approach agree that obesity is a chronic disease and that treatment must be long term. However, in the orthodox approach, the older sympathomimetic drugs, approved before the FDA required long-term trials for obesity medicine approval, are restricted to short-term use, whereas physicians using the pragmatic approach are comfortable using these drugs long term in an off-label manner. ${ }^{14,15}$ Adherents to the conventional approach point out that the older drugs are only approved for short-term use, and that no long-term randomized controlled trials (RCTs) have been conducted. Adherents to the pragmatic approach argue that short-term restrictions were added when the older drugs were approved the second time in a political compromise move with no scientific justification. ${ }^{16}$ These private practitioners argue that over 50 years of widespread safe use provides sufficient evidence since very long-term RCTs have never been done and probably never will be. ${ }^{17}$ Some advocates of the conventional approach now agree that off-label long-term use of phentermine is acceptable. ${ }^{18}$

Use of the older drugs for patients with a BMI below conventional cutoffs and long-term use are two of the most common ways in which phentermine and the other older drugs are used off-label, but there are others that will be discussed subsequently.

Lifestyle modification is an important component of comprehensive obesity treatment. One focus of such treatment is identification and mitigation of harmful eating behaviors. Recent data suggest that at least some obesity drugs induce reductions in energy intake by generating beneficial changes in cravings and eating behaviors. , $^{3,4,19}$

\section{Review of drugs used off-label for weight management}

Off-label drug use (OLDU) generally means that a drug is being used for an unapproved indication, population or at an unapproved dosage. In addition to these unapproved uses, antiobesity may be also employed for longer than recommended durations, when contraindicated, or in other ways contrary to the US FDA-approved label. Countries other than the USA typically have their own drug approval processes, but their labels commonly include language similar to that of the FDA label. Discussion of OLDU in this review is limited to US obesity medicine physicians and the US FDA label, and is intended to review some of the data on how US physicians are actually using drugs off-label. The uses of drugs that are approved for other diseases that have weight loss as a side effect and that are used in treating overweight or obese patients with the indicated diseases are not discussed.

While, in general, OLDU is neither illegal nor unethical, some jurisdictions may limit the use of specific medications for specific situations. For example, in the USA, the state of Ohio forbids proscribing any controlled substance for weight loss in any manner contrary to the FDA label (Ohio Administrative Code 4731-11-04). Penalties may include forfeiture of medical license. In addition, the state prosecutors may charge an offending doctor who dispenses medications with felony, drug trafficking and money laundering. Physicians should not presume off-label use of controlled substance antiobesity medicines is freely permitted in their own location but should investigate local regulations and laws carefully before prescribing these drugs off-label.

Drug labels are information documents produced after marketing approval but prior to marketing and are infrequently updated as new knowledge emerges from experience with the drug except when unexpected adverse effects surface. The longer a drug has been in use, the more the likelihood of its uses and benefits being discovered that were not contemplated prior to or during the approval process. Long-term usage may demonstrate that initial safety concerns that prompted warnings in the label are unfounded, but such warnings may not be removed from the label. Hence, information contained in labels of older drugs may be outdated due to unavailability of more recent research and clinical experience at the time the warnings were added to the label.

Drugs commonly used off-label for weight management are discussed in the following section.

\section{Amphetamine}

Methamphetamine (desoxyephedrine) was first approved in 1943 by the FDA for treating narcolepsy, mild depression, postencephalitic Parkinson syndrome, chronic alcoholism, cerebral arteriosclerosis, and hay fever. Later, in 1947, methamphetamine was also approved as the first drug for treating obesity. Both approvals were made at a time when when US law required the FDA to only consider whether new drugs were safe without consideration of their effectiveness. Later, in 1962, the US congress amended the Food Drug and Cosmetic Act requiring the FDA to approve new drugs 
based on their safety but only if the new drug demonstrated proven effectiveness for the stipulated indication. Today, methamphetamine remains FDA-approved for treating attention deficit and obesity and is still available as Desoxyn ${ }^{\circledR}$. Methamphetamine is a category II controlled substance and although today this drug is apparently rarely used for treating obesity, such usage is not off-label. Physicians used $5 \mathrm{mg}$ methamphetamine tablets up to 3 times daily before meals in the 1940s and 1950s for treating obesity, but then turned toward using sympathomimetic amines as these became available beginning with phenmetrazine in 1956; phentermine, diethylpropion and phendimetrazine in 1959; and benzphetamine in 1960.

\section{Phentermine}

Phentermine became the most frequently prescribed medicine for treating obesity. The originally approved indication was obesity; and the drug was used on-label until 1977 when it, along with all other drugs approved for treating obesity, were approved a second time after an amendment to the Food Drug and Cosmetic Act required that the FDA approve new drugs based on efficacy as well as safety. There was protracted opposition to re-approval from those who maintained the sympathomimetic obesity drugs that had dangerous addiction potential. No evidence of addiction had appeared during 18 years of increasingly frequent use, but the FDA re-approved them all, having silenced the opposition by announcing the drugs would be approved for short-term use only. ${ }^{16}$ The FDA has jurisdiction over pharmaceutical companies but cannot regulate medical practice, jurisdiction over which resides in the individual US states. US physicians treating obesity, well aware of these statuary boundaries, continued to use phentermine and the other sympathomimetic amine anorectic drugs off-label long-term (personal communication; WL Asher, Denver, Colorado, USA, May 2011). Surveys of prescribing practices among physicians treating obesity have confirmed that a majority of these physicians continue to prescribe the sympathomimetics off-label in this manner. ${ }^{14,15}$

Phentermine is also used off-label in several ways other than long-term. Phentermine is, and has long been, prescribed for patients whose excess adiposity is below the conventional BMI cutoffs. Maffetone et $\mathrm{al}^{1}$ have suggested the use of BMI cutoffs has seriously underestimated the extent of an "overfat pandemic comprised of people who exhibit metabolic health impairments associated with excess fat mass relative to lean body mass." They point out that there are a very large number of individuals who have excess fat mass but with BMIs below the cutoffs, that such individuals have increased health risks, and imply that some deserve treatment. Viewed from Maffetone et al's perspective, private obesity medicine practitioners have been treating these overfat patients with obesity drugs off-label despite not labeling them with the proposed terminology.

Prescribed phentermine doses higher than the limit suggested are common. The label lists $37.5 \mathrm{mg}$ per day as the "usual dose" (30 $\mathrm{mg}$ of phentermine resin is the same dose). A separate paragraph warns, "When tolerance to the anorectic effect develops, the recommended dose should not be exceeded in an attempt to increase the effect; rather, the drug should be discontinued." At the time the original phentermine label was written, tolerance was considered a prelude to addiction, but it is now well known that tolerance is not the same as dependence or addiction. The phenomenon referred to may be related both to intra-species variability of drug metabolism and dose-time induction of more rapid drug metabolism. Whatever the theoretical explanation, doses higher than $37.5 \mathrm{mg} /$ day have been found effective and safe in a number of observational studies. ${ }^{6,14,15,19-23}$

Physicians treating attention deficit use dose-to-effect titration with methamphetamine up to $1 \mathrm{mg} / \mathrm{kg} /$ day and methylphenidates up to 2 or $3 \mathrm{mg} / \mathrm{kg} / \mathrm{day} .{ }^{24}$ Attention deficit medicines have considerably greater potentials for abuse than sympathomimetic anorectics. Current treatment recommendations for attention deficit call for a starting dose of amphetamine of $0.3 \mathrm{mg} / \mathrm{kg} / \mathrm{day}$, then titrating up, if needed, to a maximum of $1.0 \mathrm{mg} / \mathrm{kg} / \mathrm{day}$. The variation in dose required for effective treatment is thought to be due to intra-individual variability in drug metabolism and plasma clearance. A study in baboons ${ }^{25}$ found that intravenous amphetamine and phentermine produced equivalent plasma levels of norepinephrine. This suggests that oral doses of these drugs would have equivalent effects in humans on plasma norepinephrine levels. Surveys indicate that the average phentermine dose employed in the USA is about $60 \mathrm{mg} /$ day, and that some physicians have used up to $112 \mathrm{mg} /$ day. These doses are comparable with the doses of amphetamine used to treat attention deficit with respect to norepinephrine plasma levels and are not excessive.

The prevalence of overweight and obesity in patients with attention deficit is high, perhaps as high as $30 \%,{ }^{26}$ and patients with this combination frequently present at weight management clinics. Some of these patients are being treated for attention deficit, but many are not. It is common knowledge among obesity medicine practitioners that obese patients with attention deficit often experience clinical improvement when treated with phentermine, particularly if they are not currently being treated for their attention deficit. Effective dosages for weight loss or maintenance for these patients vary widely but most require or tolerate higher phentermine doses than patients without attention deficit. 
The label suggests the drug not be used in pediatric patients aged $<16$ and be used with caution in older adults. Phentermine was used safely for treating overweight children by pediatricians until it became unpopular in the 1980s. There are no reports of harm from phentermine treatment in either very young or elderly patients. The surveys of obesity medicine physicians cited above indicate that a majority use phentermine in treating adolescents. The same surveys suggest that these physicians do not recognize an upper age limit for treatment. Populations selected for the long-term clinical trials for phentermine/topiramate did not include very young or very old subjects, so there are no modern clinical trial data on such populations. However, observational reports have included patients safely treated with phentermine as young as 3 years ${ }^{27}$ and as old as 88 years. ${ }^{23}$

Although there are no published data on the frequency of use, phentermine is occasionally prescribed for patients with label contraindications. Coronary artery disease, stroke, arrhythmias, congestive heart failure, and uncontrolled hypertension are listed specifically. In the absence of controlled data supporting these contraindications, there is no unambiguous evidence that suggests these conditions are absolute contraindications. However, US obesity medicine specialists, based on the known mechanism of action of phentermine, and the pathophysiology of the illness, would consider congestive heart failure, uncontrolled hypertension, untreated clinically significant arrhythmias, and severe advanced coronary artery disease to be absolute contraindications. However, in cases of less severe coronary artery disease, medically treated arrhythmias and patients who have past history of stroke, some US obesity medicine specialists would weigh the benefits of weight loss in obese, overweight and overfat subjects after a thorough assessment, that would likely include consultation with the patient's cardiologist and/or medical specialist. This viewpoint is supported by reduced mortality observed in the Sibutramine Cardiovascular Outcomes (SCOUT) trial for patients with cardiovascular disease who had moderate weight loss. ${ }^{28}$ The expectation is that the same will be discovered with cardiovascular outcome trials that the FDA has mandated for the newer obesity drugs since weight loss in overweight and obese patients induces improvement in cardiac dysfunction common in such patients. ${ }^{29}$

Other contraindications include hyperthyroidism, glaucoma and history of drug abuse. Most physicians would likely agree that phentermine not be used until hyperthyroidism has been treated but most would also agree a history of successful treatment of hyperthyroidism is not a contraindication. As with other medications that have anticholinergic side effects, phentermine is contraindicated in patients with narrow-angle glaucoma. However, it is not contraindicated in patients with open-angle glaucoma.

As will be discussed in more detail subsequently in this review, phentermine use in clinical practice has not been associated with phentermine cravings, withdrawal, or excessive use leading to psychological or physical impairment. Although there is a widespread presumption that phentermine abuse is common, actual phentermine abuse is not common and appears limited to the use of the drug as a stimulant among people trying to stay awake and those trying to boost their energy level. Phentermine is longer acting than caffeine and does not have the adverse gastrointestinal effects of high doses of caffeine, so some students studying for exams and some long-haul truck drivers use it to stay awake and alert. Evidently, some patients with stimulant use disorder who use cocaine, methamphetamine or other strong stimulants add phentermine to a drug cocktail in an attempt to heighten the stimulant effects, but no data have been published on the frequency of this practice. A telephone survey of 50 addiction treatment centers in the USA found only 2 instances of patients using such cocktails among several thousand admissions, suggesting the addition of phentermine to such cocktails is uncommon. ${ }^{30}$ Stimulant use disorder due to phentermine alone as the favored drug has not been described, and no such entity is included in the fifth edition of the Diagnostic and Statistical Manual of Mental Disorders (DSM-5) ${ }^{31}$ Clinically significant psychiatric distress similar to that described in the DSM-5 in discussing stimulant use disorders has never been observed in overweight or obese patients treated with phentermine. A phentermine withdrawal syndrome has never been observed or described. Patients with either overt attention deficit or some of its symptoms typically "like" phentermine because they function better when taking it. Patients who have difficulty staying in control of eating also "like" phentermine because they have less cravings and enjoy better control of their eating behaviors. Patients with symptoms of attention deficit are quite common among the overweight and obese. For these reasons, "liking" phentermine should not be interpreted as an indication phentermine has high abuse potential. Phentermine treatment enhances control of impulsive behavior and control of other harmful eating behaviors; these are goals of behavioral treatment in obese patients.

It may be reasonable to prescribe phentermine for subjects who have a history of recovery from drug abuse. The author has found this safe in carefully selected patients provided their recovery is genuine, recovery has endured for at least several years and phentermine does not induce phentermine cravings or desire for their former drugs of abuse. 
The label also lists contraindications that are absolute and seldom ignored, and these include recent monoamine oxidase inhibitor use, agitated states, pregnancy, nursing mothers and known hypersensitivity or idiosyncratic reactions to sympathetic amines.

\section{Phentermine label warnings}

Some consider prescribing phentermine despite specific label warnings to be an off-label use. It is recommended that the label warnings be included in an informed consent, and that any concern of the patient be thoroughly discussed and the discussion documented. The rationale for decisions to prescribe phentermine contrary to a warning would best be explicitly documented in the patient record.

\section{Co-administration with other weight-loss drugs}

US physicians view this warning as an anachronism since the FDA has approved the two combination drugs phentermine/ topiramate and bupropion/naltrexone. The warning against combining weight-loss medicines appeared in the phentermine label in 2000 after 1997 reports of valvulopathy induced by the combination of phentermine and fenfluramine, and both dexfenfluramine and fenfluramine were taken off-market. Surveys of US physicians treating obesity have revealed these physicians frequently combined the various antiobesity drugs with other drugs approved for obesity and with a variety of other drugs that have an effect on weight loss. For example, these physicians combined phentermine and topiramate long before the FDA approved a fixed dose combination (Qsymia) in 2012. Other combinations in use are discussed.

\section{Primary pulmonary hypertension (PPH)}

PPH has not been associated with phentermine monotherapy. As discussed in a previous communication, isolated reports of $\mathrm{PPH}$ occurring in patients who have taken phentermine have relied on theoretical but unproven adverse effects and ignored the underlying incidence of idiopathic pulmonary hypertension. ${ }^{32}$

\section{Valvular heart disease}

This warning first appeared in the label in 2000 after valvulopathy was discovered in patients taking phentermine and fenfluramine in 1997 and before publication of a report suggesting that fenfluramine, but not phentermine, activated cardiac $5 \mathrm{HT}_{2 \mathrm{~B}}$ serotonin receptors that then induced valvulopathy. ${ }^{33}$ Although the label states " ... there have been rare cases of valvular heart disease in patients who reportedly have taken phentermine alone," there are no such reports in the peer-reviewed medical literature.

\section{Tolerance}

Tolerance refers to a reduced response to a drug after repeated use. Tolerance is a normal physiologic process that occurs with substances of abuse but also with some medicines (e.g., diphenhydramine). Tachyphylaxis refers to very rapid development of tolerance. For additional discussion, see the "Risk of Abuse and Addiction" section.

\section{Hazardous task ability}

Labels for most drugs that work in the central nervous system include this warning. There is no specific evidence that phentermine degrades mental or physical performance. Generally, stimulants will enhance rather than degrade mental and physical performance until extremely high doses are used. The Federal Aviation Administration (FAA) has not accepted phentermine for pilots. The only antiobesity drug acceptable to the FAA is orlistat.

\section{Risk of abuse and addiction}

The DSM- $5^{31}$ does not have criteria for "addiction" but instead sets forth criteria for diagnosing stimulant-related disorders and discusses "stimulant use disorder" and "stimulant withdrawal" with amphetamine and cocaine as prototypical stimulants. Phentermine is not specifically mentioned in the DSM-5. A PubMed search for "phentermine" (February 21,2017$)$ revealed 1371 papers in the peer-reviewed medical literature. In all of this extensive literature, nothing resembling stimulant use disorder with phentermine as the substance or stimulant withdrawal due to phentermine has been described. Stimulant use disorder is defined as a pattern of repeated use leading to clinically significant impairment or distress as manifested by two or more of a list of 11 symptoms, including intense cravings for the substance leading to self-destructive social and job or profession-related behaviors. In phentermine post-marketing studies, we found that long-term phentermine use, even at doses higher than $37.5 \mathrm{mg} /$ day, did not induce phentermine cravings, and that abrupt cessation of long-term phentermine did not induce a stimulant withdrawal syndrome. . $^{23,34}$

Assessment of drug "liking" is currently used as a measure of addiction potential. ${ }^{35}$ Phentermine has been used in studies as an example of a liked drug. ${ }^{36}$ However, patients taking phentermine often "like" the drug for a variety of valid reasons but do not have other signs or symptoms of addiction or physical dependence. Some like phentermine because they have lost weight taking it and enjoy a better quality of life. Many patients in medical weight management programs have adult attention deficit or at least some symptoms of attention 
deficit, and many are not taking specific attention medicines. These patients typically are less scattered, can focus better and are more productive when taking phentermine and, realizing this, "like" taking the drug. Discussions of drug liking of phentermine as a sign of addiction typically fail to consider the prevalence of attention deficit in the obese population as a reason for drug liking. Nor do such discussions differentiate between hedonic drug liking versus drug liking because of medical benefits.

\section{Use with alcohol}

There is an extensive literature on the effects of ethanol and a wide variety of stimulants in animals and humans. (A PubMed search for "stimulants and ethanol" [February 21, 2017] yielded 2,255 papers.) However, there are no specific reports on the effects of combining phentermine and ethanol in humans among 15 papers yielded in a PubMed search for "phentermine and ethanol" on the same date. Thus, it is not clear why the phentermine label includes this warning. FDA labels of many drugs acting in the central nervous system include cautions regarding combining such drugs and alcohol, so this may be a generic caution.

\section{Hypertension}

Phentermine-induced increases in blood pressure are often mentioned in both the medical and general literature, but few instances have been recorded. ${ }^{37}$ US obesity medicine practitioners typically do not prescribe phentermine with poorly controlled hypertension until it is under control, but they do prescribe it in the presence of controlled hypertension, then monitor the patient's blood pressure closely, discontinuing phentermine if blood pressure rises.

\section{Diabetic medicines}

It is appropriate to monitor blood sugars during treatment for obesity since dose lowering or elimination of diabetic medicines is often a benefit and is to be expected with weight loss. Phentermine is not contraindicated in patients with either treated or untreated diabetes.

\section{Metformin}

Although the label for metformin specifies diabetes as the sole indication, the drug has been prescribed with increasing frequency for overweight and obese patients with impaired fasting glucose following a report that long-term metformin delayed or prevented diabetes and induced weight loss in such patients. ${ }^{38}$ Metformin is known to induce modest weight loss in overweight patients even without glucose abnormalities and is prescribed off-label as an adjunct to weight loss..$^{39,40}$

\section{Topiramate}

Topiramate was FDA-approved for treatment of refractory epilepsy in 1996. Weight loss was immediately noted as a side effect. ${ }^{41}$ Soon thereafter, reports began appearing that topiramate was effective in treating binge eating disorder ${ }^{42}$ and obesity. ${ }^{43}$ A survey of US obesity medicine physicians performed in early 2008 and published in 2009 revealed that $50 \%$ were prescribing topiramate as monotherapy for obesity. ${ }^{14}$ In 2012, in a survey conducted before the FDA approved the combination phentermine and topiramate for obesity, $63 \%$ of those surveyed were already using topiramate for treating obesity and $61 \%$ were combining it with phentermine in some patients. ${ }^{15}$ Thus, topiramate has been used off-label, both as monotherapy and in combination. Phentermine/topiramate (Qysmia) is discussed next as it is also used off-label.

\section{Sympathomimetics other than phentermine}

Other sympathomimetics include diethylpropion (1959), and phendimetrazine (1959), both of which have FDA-approved labels with indications, contraindications and warnings identical or similar to those in the phentermine label. Diethylpropion is a category IV controlled substance, and phendimetrazine is a category III. Both drugs are frequently used off-label in the US in manners similar to phentermine. In the 2012 survey, $63 \%$ of surveyed physicians used diethylpropion in an average of $18 \%$ of their patients and $60 \%$ used phendimetrazine in an average of $20 \%$ of their patients. Benzphetamine, a category III drug, is another older sympathomimetic drug that is still in use but apparently less often used than diethylpropion or phendimetrazine. The surveys did not include questions regarding benzphetamine, so we have no data but answers to queries to US pharmaceutical wholesalers reveal that their benzphetamine sales are much lower than the other sympathomimetics.

\section{Phentermine/topiramate (Qsymia)}

The FDA approved fixed-dose phentermine/topiramate for obesity in 2012. The label includes warnings from both phentermine and topiramate labels but interestingly does not include all of the contraindications of the phentermine label. Contraindications include only pregnancy, glaucoma, hyperthyroidism during or within 14 days of taking monoamine 
oxidase inhibitors and known hypersensitivity or idiosyncrasy to sympathomimetic amines. Since the maximum dose of phentermine in the combination is $15 \mathrm{mg} /$ day, some US physicians prescribe additional phentermine, a combination which is an off-label use of both phentermine/topiramate and phentermine.

\section{Lorcaserin (Belviq)}

Lorcaserin, approved as a category IV drug in 2012, is used on-label as monotherapy but after reports from a pilot trial comparing phentermine monotherapy, lorcaserin monotherapy, and a combination of both showed that the combination induced greater weight loss than either drug alone, obesity medicine physicians began using the off-label combination. ${ }^{44}$ This was no surprise since $52 \%$ of respondents in the 2012 survey had indicated they would try the off-label combination once lorcaserin was approved. It is common knowledge that the two are being used in combination, but as yet there are no data on the frequency of use.

\section{Naltrexone/bupropion (Contrave)}

Naltrexone, originally approved for treating opioid dependence and later found to be useful for alcohol addiction, combined with bupropion was approved for obesity in 2014 . Some physicians combine this drug with phentermine. There are no data on the frequency of use of such a combination.

\section{Liraglutide (Victoza ${ }^{\circledR}$, Saxenda)}

Liraglutide, approved as Victoza for diabetes in 2010, also induced weight loss in overweight diabetics. Saxenda is a higher dose approved for weight loss for obesity. There are no current data on off-label use of liraglutide with either dose form but it is likely some specialists have tried combining it with phentermine.

\section{Drugs approved for uses other than obesity}

Certain drugs approved for indications other than obesity but inducing weight loss when given on-label to overweight patients could potentially be used off-label to treat overweight and obese patients who do not have the indicated diagnosis. There is little or no data on whether any of these are actually being used off-label for obesity, but given the proclivity of obesity practitioners to adopt drugs that induce weight loss without regard to approved indications, one can expect some to use these off-label drugs for weight loss. Some of these drug candidates for off-label use are listed in the following section.
Sodium-glucose cotransporter-2 (SGLT2) inhibitors

SGLT2 inhibitors, including canagliflozin, dapagliflozin, and empagliflozin, are FDA-approved for use with diet and exercise to lower blood sugar in adults with type 2 diabetes. In diabetics, these also induce modest weight loss. A recent report of a trial combining canagliflozen and phentermine for overweight patients without diabetes suggests this off-label combination can induce weight loss superior to diet and lifestyle modification without these medications. ${ }^{45}$

\section{Exenatide}

Approved for treating diabetes, exenatide also induces weight loss in overweight diabetics. ${ }^{46}$ This drug has been used offlabel for weight loss, but apparently infrequently.

\section{Zonisamide}

Approved for epilepsy, this drug induces weight loss and has been used off-label alone $e^{47}$ or in combination with bupropion $^{48}$ or phentermine.

\section{Bupropion}

Another substituted phenethylamine approved as an antidepressant is a norepinephrine-dopamine reuptake inhibitor, which commonly induces modest weight loss. The drug has been used frequently off-label as a weight loss agent, often in combination with phentermine or other weight loss drugs.

\section{Pramlinitide}

Approved for diabetes, the drug induces weight loss in overweight diabetics. After early reports of successful use for weight loss in nondiabetic patients, ${ }^{49}$ physicians began using it off-label to treat obesity. ${ }^{14}$

\section{Metreleptin}

Approved for congenital or acquired generalized lipodystrophy, metreleptin is a synthetic leptin analog. Obese patients typically have high circulating leptin levels, and clinical trials have shown that leptin administration does not induce weight loss. However, leptin levels fall during weight loss and remain low afterward, ${ }^{50}$ and leptin administration after weight loss in obese patients reverses some of the neuroendrocrine adaptations involved in weight regain. ${ }^{51}$ These data suggest that daily leptin injections could possibly be useful in preventing weight regain after a significant weight loss. Since FDA-mandated Risk Evaluation and Mitigation Strategies (REMS) for metreleptin rigidly restrict the use of this leptin analog to patients with generalized lipodystrophy 
on a case-by-case basis, it is unlikely the drug has been used off-label for weight loss maintenance. Resolution of the issue whether or not leptin analogs will be a solution to the problem of weight regain will require further research.

\section{Other combinations}

Combinations of drugs with differing mechanisms of action have been typically proven to induce greater weight loss than monotherapy. US physicians have not been hesitant to try a wide variety of combinations of drugs known to induce weight loss. Although data on this practice are scarce, one can predict that phentermine is the most frequently combined drug.

Phentermine and L-5-hydroxytryptophan/carbidopa is an off-label combination that was popular before lorcaserin became available. ${ }^{14}$

Phentermine and fluoxetine was a combination used frequently in the 1990 s but is apparently used less often now. ${ }^{52}$

\section{Role of the practitioner and considerations for government drug regulators}

Practitioners have a professional obligation to provide optimum care to their patients, to explain to them the individual health risks discovered, and to explain risks and benefits of any needed treatment. Treatment decisions should then be mutually agreed to between a knowledgeable physician and a well-informed patient. Guidelines and labels can be helpful but cannot substitute or replace this interaction between a physician and patient. Just as any form of treatment, offlabel prescribing may offer benefits unique to the individual but may carry attendant risks. Since off-label prescribing is controversial, physicians should be especially thorough in informing themselves and their patients before undertaking such treatment and especially careful in their documentation. US physicians should be reminded that the FDA is not empowered to regulate medical practice, and that individual state medical licensing boards regulate medical practice in the US. Hence, there are no federal laws regulating off-label medication use, although some individual states' medical boards may have restrictive regulations.

The FDA and comparable agencies in other nations should be aware that practicing physicians and academic physicians are moving toward using measures of body fat beyond weight and BMI for diagnosis and risk assessment, and that many now believe BMI-centric obesity diagnosis is archaic and should be either replaced or enhanced with measures of body fat, especially in the overfat but not yet overweight or obese. Many of the contraindications and warnings in the older drug labels are based on presumptions that have proven to be unsubstantiated. Exclusive use of BMI thresholds as indications and erroneous warnings on the labels inhibit employment of useful weapons against the pandemic and deny overfat patients effective treatment. These should be removed from the labels.

\section{Discussion}

The current paradigm for identifying and treating excess adiposity focuses on the late stages of what is commonly a progressive chronic illness. While BMI cutoffs for identification and diagnosis of excess adiposity are highly specific for identifying obesity and for indicating advanced disease, BMI values are not sensitive enough to identify patients in the early stages of pathologic adipose tissue accumulation. The established paradigm ignores both the early disease and the fact that the trajectory of the illness is for many relentlessly progressive. Even modest amounts of adipose accumulation have adverse health implications, and if left untreated, are associated with increases in mortality rates. ${ }^{53}$ Although the notion of metabolically healthy obesity persists, these reports often ignore the trajectory of the disease and fail to recognize that being healthy is often a transitory state in an obese patient. ${ }^{54-56}$

As we have discussed earlier, off-label prescribing is very common among US physicians who treat obesity. The FDA and academic physicians insist that only evidence from RCTs should be trusted and denigrate clinical experience and observational studies. Clinicians, on the other hand, have taken a more pragmatic approach by giving much higher credence to shared clinical experience, particularly in situations where favorable outcomes have consistently been observed over decades.

Additionally, clinicians have long paid more attention to excess fat stores as an indicator of disease and less attention to BMI thresholds, particularly for the overfat with BMIs below the thresholds. Many believe BMI is too insensitive for diagnosis and using BMI fails to identify patients who would be better served if treated early. ${ }^{10,11}$ Furthermore, labeling what is now recognized as a progressive chronic illness with a name for its late stage has directed attention and research away from the early stages. Thus, naming the disease as obesity has detracted from care for patients in early stages when treatment could be expected to be more successful. Maffetone et al have suggested that a better term would be overfat, ${ }^{1}$ and that based on a 2014 world population estimate of 7.2 billion, $62 \%$ to $76 \%$ or 4.5 to 5.5 billion people are overfat. Now, 2.8 to 3.5 billion are overweight or 
obese according to the BMI thresholds, meaning up to 2.7 billion of the world population is overfat with a BMI of $<27$. US physicians following the leadership of the ASBP have frequently treated with pharmacotherapy the overfat not classified by BMI as either overweight or obese. This alone accounts for a major proportion of OLDU in treating obesity.

US physicians offer several reasons for using pharmacotherapy both on-label and off-label. 1) Obesity treatment that omits pharmacotherapy has been a dismal failure. The best the diabetes prevention trial could come up with was a $5 \%$ weight loss at 8 years. ${ }^{57}$ Other trials have had equally dismal results. The average weight of a patient in an US obesity clinic is $\sim 220$ pounds or $100 \mathrm{~kg}$. An 8-year loss of 5\% therefore represents $5 \mathrm{~kg}$ or 11 pounds, a loss statistically significant in terms of risk reduction but far from satisfactory to the patient. 2) The addition of pharmacotherapy to usual medical treatment improves the weight loss outcome significantly. A widely cited trial compared diet and lifestyle modification with diet and sibutramine alone and with the combination of diet, lifestyle modification and sibutramine. The sibutramine only patients lost an average of $4.6 \%$, the lifestyle modification group lost $6.4 \%$, and the combined group lost an average $11.2 \%$ at 1 year. ${ }^{58}$ Weight loss outcomes reported in actual practice have been even better. One observational study in a private practice compared weight loss of a ketogenic diet and lifestyle behavior modification with and without the addition of phentermine. The phentermine-treated patients had an average weight loss of $17.6 \%$, and the phentermine untreated patients had an average weight loss of $12.8 \%$, a significant difference. ${ }^{6}$ The same study also found that patients on long-term phentermine were more successful with weight loss maintenance. 3) After several years of experience with the new drugs, some US physicians are concluding that phentermine is still the first choice drug, and that it must be used as long-term off-label for the best outcome for their patients. 4) US physicians have also found the drugs useful for more than weight loss. Arresting or retarding iatrogenic weight gain that may be induced by a wide variety of drugs is sometimes possible. Pharmacotherapy may also arrest progressive weight gain caused by a variety of other reasons. Prevention of weight gain is beneficial to patient's health even in the absence of weight loss.

\section{Conclusion and future directions}

The conventional paradigm is appropriate for patients diagnosed as obese, morbidly obese, and super obese with a BMI exceeding accepted cutoffs. Clearly, once excess fat accumulation is reflected by a BMI of 30 or 35 or more; the illness is irreversible, incurable but manageable with surgical or medical care. The treatment most successful for patients with a high BMI is bariatric surgery. Unfortunately, most of the patients deserving surgical treatment will not receive it since there are only sufficient global surgical and monetary resources to treat some of them. The only options for the remainder will be either no treatment or lifelong medical management to mitigate obesity-associated damage and illnesses.

While the current paradigm for obesity diagnosis and treatment is suitable for those with a high BMI, the paradigm is flawed for patients with lower BMIs in the early stages of abnormal adipose tissue accumulation who are often ignored and left untreated. Perhaps this is one reason the existing paradigm has made no impact on the global pandemic of obesity; instead, it fosters continuation of worldwide obesity by allowing early stage patients to accumulate ever-higher amounts of adipose tissue. The endemic will likely continue to expand unless more attention is given to treating early stage patients and to prevention. Clearly, one avenue toward prevention should be identification and treatment of the disease process we call obesity in its incipient stages. For these reasons, the paradigm should therefore be expanded by: 1) inclusion of direct measurement of body fat for diagnosis so that patients with excess adipose accumulation whose BMI is $<27$ are identified and treated, and 2) recognition that early excess fat accumulation should be treated and treatment should include pharmacotherapy.

That antiobesity drugs are more dangerous than the illness itself is implicit in the current conventional paradigm, in the FDA guidelines for obesity drug development for the pharmaceutical industry ${ }^{59}$ and in the drug labels. Although never expressed openly in any of these documents, FDA concern of the dangers of approving an obesity drug with unforeseen adverse effects has often been voiced in advisory committees considering obesity drugs. Interests of overfat patients worldwide would be served better if all the effective obesity drugs became widely used. FDA-mandated REMS for newly approved obesity drugs are typically stratagems intended to limit their use because the FDA fears unintended adverse effects. Unfounded label cautions for the older drugs have also limited the use of these drugs. This pervasive risk-averse attitude among FDA staff and many of their physician advisors is a major barrier both to new obesity drug development and to the use of the older drugs.

Thus, the treatment paradigm should explicitly acknowledge that the disease is far more dangerous than any of the medicines in current use. The paradigm should also acknowledge that guidelines should not replace treatment decisions 
made according to an individual physician's judgment and the clinical needs of an individual patient.

OLDU for obesity treatment is very common in the USA and will likely continue in the future, given the paucity of approved drugs for treating obesity and the current regulatory environment.

\section{Acknowledgment}

This work received funding for research from the ASBP and the Obesity Treatment Foundation.

\section{Disclosure}

The author has served as a speaker for Eurodrug Laboratories, Akrimax Pharmaceuticals, Vivus Pharmaceuticals, iNova Pharmaceuticals and Radiant Health; and has consulted for CTS Group, Citius Pharmaceuticals, Rodman and Renshaw, GLG Research, Credit Suisse, and WallachBeth Capital LLC.

\section{References}

1. Maffetone PB, Rivera-Dominguez I, Laursen PB. Overfat and underfat: new terms and definitions long overdue. Front Public Health, 2016;4:279.

2. Halford JC, Boyland EJ, Blundell JE, Kirkham TC, Harrold JA. Pharmacological management of appetite expression in obesity. Nat Rev Endocrinol. 2010;6(5):255-269.

3. Greenway FL, Fujioka K, Plodkowski RA, et al. Effect of naltrexone plus bupropion on weight loss in overweight and obese adults (COR-I): a multicentre, randomised, double-blind, placebo-controlled, phase 3 trial. Lancet. 2010;376(9741):595-605.

4. Rebello CJ, Greenway FL. Reward-induced eating: therapeutic approaches to addressing food cravings. Adv Ther. 2016;33(11):1853-1866.

5. Thomas EA, Mcnair B, Bechtell JL, Ferland A, Cornier MA, Eckel RH. Greater hunger and less restraint predict weight loss success with phentermine treatment. Obesity (Silver Spring). 2016;24(1):37-43.

6. Hendricks EJ, Greenway FL, Westman EC, Gupta AK. Blood pressure and heart rate effects, weight loss and maintenance during long-term phentermine pharmacotherapy for obesity. Obesity (Silver Spring). 2011;19(12):2351-2360.

7. CenterWatch. [database on the Internet]. FDA Approved Drugs by Therapeutic Area. Available from: http://www.centerwatch.com/druginformation/fda-approved-drugs/therapeutic-area/4/endocrinology. Accessed May 23, 2017.

8. Thomas CE, Mauer EA, Shukla AP, Rathi S, Aronne LJ. Low adoption of weight loss medications: a comparison of prescribing patterns of antiobesity pharmacotherapies and SGLT2s. Obesity (Silver Spring). 2016;24(9):1955-1961.

9. Bhat SP, Sharma A. Current drug targets in obesity pharmacotherapy - a review. Curr Drug Targets. Epub 2017 Feb 27.

10. Okorodudu DO, Jumean MF, Montori VM, et al. Diagnostic performance of body mass index to identify obesity as defined by body adiposity: a systematic review and meta-analysis. Int J Obes. 2010;34(5):791-799.

11. Shah NR, Braverman ER. Measuring adiposity in patients: the utility of body mass index (BMI), percent body fat, and leptin. PLoS One. 2012;7(4):e33308.

12. Blundell JE, Dulloo AG, Salvador J, Frühbeck G; EASO SAB Working Group on BMI. Beyond BMI - phenotyping the obesities. Obesity Facts. 2014;7(5):322-328.

13. Boulenouar S, Michelet X, Duquette D, et al. Adipose type one innate lymphoid cells regulate macrophage homeostasis through targeted cytotoxicity. Immunity. 2017;46(2):273-286.
14. Hendricks EJ, Rothman RB, Greenway FL. How physician obesity specialists use drugs to treat obesity. Obesity (Silver Spring). 2009;17(9):1730-1735.

15. Schmidt SL, Bryman D, Greenway FL, Hendricks EJ. How physician obesity medicine specialists treated obesity before 2012 new drug approvals. Obes Surg. 2015;25(1):186-190.

16. Colman E. Anorectics on trial: a half century of federal regulation of prescription appetite suppressants. Ann Intern Med. 2005;143(5):380-385.

17. Frank A. The long-term management of obesity with continuing pharmacotherapy. Obes Res. 2004;12(11):1821-1827.

18. Apovian CM, Aronne LJ, Bessesen DH, et al. Pharmacological management of obesity: an endocrine Society clinical practice guideline. J Clin Endocrinol Metab. 2015;100(2):342-362.

19. Miguelgorry PL, Hendricks EJ. Pharmacotherapy for obesity and changes in eating behavior: a patient and physician's perspective. $A d v$ Ther. 2016;33(7):1262-1266.

20. Douglas A, Douglas JG, Robertson CE, Munro JF. Plasma phentermine levels, weight loss and side-effects. Int J Obes. 1983;7(6):591-595.

21. Haddock CK, Poston WS, Foreyt JP, DiBartolomeo JJ, Warner PO. Effectiveness of Medifast supplements combined with obesity pharmacotherapy: a clinical program evaluation. Eat Weight Disord. 2008;13(2):95-101.

22. Rothman RB. Treatment of obesity with combination pharmacotherapy. Am J Ther. 2010;17(6):596-603.

23. Hendricks EJ, Srisurapanont M, Schmidt SL, et al. Addiction potential of phentermine prescribed during long-term treatment of obesity. Int $J$ Obes (Lond). 2014;38(2):292-298.

24. Stevens JR, Wilens TE, Stern TA. Using stimulants for attention-deficit/ hyperactivity disorder: clinical approaches and challenges. Prim Care Companion CNS Disord. 2013;15(2).

25. Alexander M, Rothman RB, Baumann MH, Endres CJ, Brasic JR, Wong DF. Noradrenergic and dopaminergic effects of (+)-amphetamine-like stimulants in the baboon Papio anubis. Synapse. 2005;56(2):94-99.

26. Pagoto SL, Curtin C, Lemon SC, et al. Association between adult attention deficit/hyperactivity disorder and obesity in the US population. Obesity (Silver Spring). 2009;17(3):539-544.

27. Lorber J. Obesity in childhood. A controlled trial of anorectic drugs. Arch Dis Child. 1966;41(217):309-312.

28. Caterson ID, Finer N, Coutinho W, et al. Maintained intentional weight loss reduces cardiovascular outcomes: results from the Sibutramine Cardiovascular OUTcomes (SCOUT) trial. Diabetes Obes Metab. 2012;14(6):523-530.

29. de las Fuentes L, Waggoner AD, Mohammed BS, et al. Effect of moderate diet-induced weight loss and weight regain on cardiovascular structure and function. J Am Coll Cardiol. 2009;54(25):2376-2381.

30. Bryman D, Hendricks EJ, Schmidt SL. Incidence of addiction and abuse due to phentermine, diethylpropion, and phendimetrazine in the United States. In. Telephone Survey of Emergency Rooms and Addiction Treatment Centers ed. Unpublished manuscript, 2013.

31. American Psychiatric Association, DSM-5 Task Force. Diagnostic and Statistical Manual of Mental Disorders: DSM-5, 5th ed. American Psychiatric Association: Arlington, VA. 2013.

32. Hendricks EJ, Rothman RB. RE: pulmonary hypertension associated with use of phentermine? Yonsei Med J. 2011;52(5):869-870.

33. Rothman RB, Baumann MH, Savage JE, et al. Evidence for possible involvement of 5-HT(2B) receptors in the cardiac valvulopathy associated with fenfluramine and other serotonergic medications. Circulation. 2000;102(23):2836-2841.

34. Hendricks EJ, Greenway FL. A study of abrupt phentermine cessation in patients in a weight management program. Am J Ther. 2011;18(4):292-299.

35. Berridge KC, Robinson TE. Liking, wanting, and the incentivesensitization theory of addiction. Am Psychol. 2016;71(8):670-679.

36. Schoedel KA, Addy C, Chakraborty B, et al. Human abuse potential and cognitive effects of taranabant, a cannabinoid 1 receptor inverse agonist: a randomized, double-blind, placebo- and active-controlled, crossover study in recreational polydrug users. J Clin Psychopharmacol. 2012;32(4):492-502. 
37. Hendricks EJ, Rothman RB. Phentermine therapy for obesity does not elevate blood pressure. Diabetes Obes Metab. 2011;13(10): 963-964.

38. Diabetes Prevention Program Research Group. Long-term safety, tolerability, and weight loss associated with metformin in the Diabetes Prevention Program Outcomes Study. Diabetes Care. 2012;35(4): 731-737.

39. Seifarth C, Schehler B, Schneider HJ. Effectiveness of metformin on weight loss in non-diabetic individuals with obesity. Exp Clin Endocrinol Diabetes. 2013;121(1):27-31.

40. Igel LI, Sinha A, Saunders KH, Apovian CM, Vojta D, Aronne LJ. Metformin: an old therapy that deserves a new indication for the treatment of obesity. Curr Atheroscler Rep. 2016;18(4):16.

41. Shorvon SD. Safety of topiramate: adverse events and relationships to dosing. Epilepsia 1996;37(Supp1 2):S18-S22.

42. Shapira NA, Goldsmith TD, McElroy SL. Treatment of binge-eating disorder with topiramate: a clinical case series. J Clin Psychiatry. 2000;61(5):368-372.

43. Bray GA, Hollander P, Klein S, et al. A 6-month randomized, placebocontrolled, dose-ranging trial of topiramate for weight loss in obesity. Obes Res. 2003;11(6):722-733.

44. Smith SR, Garvey WT, Greenway FL, et al. Coadministration of lorcaserin and phentermine for weight management: a 12-week, randomized, pilot safety study. Obesity (Silver Spring). 2017;25(5): $857-865$.

45. Hollander P, Bays HE, Rosenstock J, et al. Coadministration of canagliflozin and phentermine for weight management in overweight and obese individuals without diabetes: a randomized clinical trial. Diabetes Care. 2017;40(5):632-639.

46. McAdam-Marx C, Nguyen H, Schauerhamer MB, et al. Glycemic control and weight outcomes for exenatide once weekly versus liraglutide in patients with type 2 diabetes: a 1-year retrospective cohort analysis. Clin Ther. 2016;38(12):2642-2651.

47. Gadde KM, Kopping MF, Wagner HR 2nd, Yonish GM, Allison DB, Bray GA. Zonisamide for weight reduction in obese adults: a 1-year randomized controlled trial. Arch Intern Med. 2012;172(20): $1557-1564$.
48. Gadde KM, Yonish GM, Foust MS, Wagner HR. Combination therapy of zonisamide and bupropion for weight reduction in obese women: a preliminary, randomized, open-label study. J Clin Psychiatry. 2007;68(8): 1226-1229.

49. Aronne L, Fujioka K, Aroda V, et al. Progressive reduction in body weight after treatment with the amylin analog pramlintide in obese subjects: a Phase 2, randomized, placebo-controlled, dose-escalation study. J Clin Endocrinol Metab. 2007;92(8):2977-2983.

50. Sumithran P, Prendergast LA, Delbridge E, et al. Long-term persistence of hormonal adaptations to weight loss. $N$ Engl J Med. 2011;365(17): 1597-1604

51. Rosenbaum M, Leibel RL. Brain reorganization following weight loss. Nestle Nutr Inst Workshop Ser. 2012;73:1-20.

52. Whigham LD, Dhurandhar NV, Rahko PS, Atkinson RL. Comparison of combinations of drugs for treatment of obesity: body weight and echocardiographic status. Int J Obes (Lond). 2007;31(5):850-857.

53. Yu E, Ley SH, Manson JE, et al. Weight history and all-cause and cause-specific mortality in three prospective cohort studies. Ann Intern Med. 2017;166(9):613-620.

54. Lin L, Peng K, Du R, et al. Metabolically healthy obesity and incident chronic kidney disease: The role of systemic inflammation in a prospective study. Obesity (Silver Spring). 2017;25(3):634-641.

55. Navarro-Gonzalez D, Sanchez-Inigo L, Fernandez-Montero A, PastranaDelgado J, Alfredo Martinez J. Are all metabolically healthy individuals with obesity at the same risk of diabetes onset? Obesity (Silver Spring). 2016; 24(12):2615-2623.

56. Chang Y, Ryu S, Choi Y, et al. Metabolically healthy obesity and development of chronic kidney disease: a cohort study. Ann Intern Med. 2016;164(5):305-312.

57. Montesi L, El Ghoch M, Brodosi L, Calugi S, Marchesini G, Dalle Grave R. Long-term weight loss maintenance for obesity: a multidisciplinary approach. Diabetes Metab Syndr Obes 2016;9:37-46.

58. Wadden TA, Berkowitz RI, Womble LG, et al. Randomized trial of lifestyle modification and pharmacotherapy for obesity. NEngl J Med. 2005;353(20):2111-2120.

59. FDA. Guidance for the Clinical Evaluation of Weight-Control Drugs. In: CDER (ed). Washington, DC: Food and Drug Administration; 1996.

\section{Publish your work in this journal}

Diabetes, Metabolic Syndrome and Obesity: Targets and Therapy is an international, peer-reviewed open-access journal committed to the rapid publication of the latest laboratory and clinical findings in the fields of diabetes, metabolic syndrome and obesity research. Original research, review, case reports, hypothesis formation, expert opinion and commentaries are all considered for publication. The manuscript management system is completely online and includes a very quick and fair peer-review system, which is all easy to use. Visit http://www.dovepress.com/testimonials.php to read real quotes from published authors. 